\title{
A magnesium-aluminium composite produced by high-pressure torsion
}

\author{
Moara M. Castro ${ }^{1}$, Shima Sabbaghianrad ${ }^{2}$, Pedro Henrique R. Pereira ${ }^{1}$, \\ Eric M. Mazzer ${ }^{1}$, Augusta Isaac ${ }^{1}$, Terence G. Langdon ${ }^{2,3}$, Roberto B. Figueiredo ${ }^{1}$ \\ ${ }^{1}$ Department of Metallurgical and Materials Engineering, \\ Universidade Federal de Minas Gerais, Belo Horizonte, MG 31270-901, Brazil \\ ${ }^{2}$ Department of Aerospace \& Mechanical Engineering and Materials Science, \\ University of Southern California, Los Angeles, CA 90089-1453, USA \\ ${ }^{3}$ Materials Research Group, Department of Mechanical Engineering, \\ University of Southampton, Southampton SO17 1BJ, UK
}

\begin{abstract}
A magnesium / aluminium composite was produced by room temperature consolidation through high-pressure torsion (HPT) processing. Half-discs of the pure metals were placed side-by-side and subjected to different numbers of turns. The initially reduced interface between the phases gradually increased with increasing rotation. The composite displayed a significant ductility even after 10 turns. The distribution of hardness in the HPT-processed discs was bi-modal in the early stages of processing. As the number of turns increased and the thickness of the phases decreased there was a noticeable increase in hardness. The hardness values of the composite further increased after thermal treatment due to the formation of intermetallics within the interface between the magnesium and aluminium-rich phases.
\end{abstract}

Keywords: high-pressure torsion; intermetallics; magnesium / aluminium composite; thermal treatment.

*corresponding author: figueiredo@demet.ufmg.br 


\section{Introduction}

High-pressure torsion (HPT) has been used extensively to introduce severe plastic deformation into metallic materials leading to grain refinement down to the sub-micron or nanometre scale. In this metal forming technique the sample, usually in the shape of a thin disc, is compressed between rigid anvils and subjected to plastic deformation by torsion [1]. The hydrostatic compressive stresses developed during processing are in the range of a few GPa and the effective strains can easily reach values of more than 100. In addition to structural refinement, these straining conditions also promote the welding of metallic pieces. The effective stresses can overcome the material yield stress giving rise to a "fluid-like" behaviour in which the pieces come into full contact. In addition, the severe plastic deformation increases their surface area by breaking the oxide layer and promoting a metal-to-metal contact and welding [2-6].

Accordingly, HPT processing has been used to consolidate metallic chips and particles and to incorporate a hard phase into a metallic matrix to produce composites [7-10]. As the processing can be conducted at relatively low temperatures, it is possible to join dissimilar metals and to prevent the formation of intermetallics due to the limited atomic mobility. Recent reports showed that it was possible to join magnesium and aluminium by using stacked discs in order to produce composites [11-14]. Nevertheless, although the processing occurred at room temperature, the formation of $\mathrm{Al}_{12} \mathrm{Mg}_{17}$ [11-14] and $\mathrm{Al}_{3} \mathrm{Mg}_{2}$ [11, 13] intermetallics was reported. $\mathrm{A}$ nanocomposite with an average grain size of $\sim 60 \mathrm{~nm}$ in the metallic matrix and intermetallics was formed after processing through 20 turns of HPT and this composite achieved a remarkably high hardness value of $~ 330 \mathrm{Hv}[11]$.

It is known that pure aluminium [15] and pure magnesium [16] exhibit significant ductility after HPT processing but the presence of intermetallics may impair the ductility of pure metals. To investigate this problem, the present research was initiated whereby HPT was used to produce a $\mathrm{Mg} / \mathrm{Al}$ composite without the formation of intermetallics and the ductility was evaluated together with the potential for increasing the mechanical strength through subsequent thermal treatment. 


\section{Experimental materials and procedure}

The materials used in these experiments were commercial purity magnesium $(>99.7 \%$ purity) and high-purity aluminium (99.99\%). Discs of $10 \mathrm{~mm}$ diameter and $\sim 0.85 \mathrm{~mm}$ thickness were machined and cut halfway through the diameter. Composites of $\mathrm{Mg}-50 \%$ vol. Al were produced using half disks of magnesium and half disks of aluminium placed next to each other inside the $10 \mathrm{~mm}$ diameter internal cavity of a quasi-constrained HPT anvil [17] and processed through 1/4, 1, 5 and 10 turns at room temperature (RT) under a nominal pressure of 6 GPa. The top and bottom surfaces of the Mg disc were marked with black ink prior to HPT and careful observations revealed no slippage after processing and negligible mixing of the different metals on the surface. The sample set up aimed to provide conditions for mixing the phases and controlling the thickness. A similar procedure was developed to produce multilayered structure using tube high pressure shearing [18]. This also reduces the initial contact surface area between the different metals and promotes a continuous increase in such interfaces so that it is expected to improve the binding of the different phases.

The mechanical properties were determined using dynamic hardness and miniature tensile testing. The dynamic hardness was carried out using an ultra-microhardness tester model Shimadzu DUH-211S equipped with a Berkovich indenter. The maximum load was $100 \mathrm{mN}$ and there was no dwell time. Miniature samples were machined for the tensile tests having $1.5 \mathrm{~mm}$ gauge length, $1.0 \mathrm{~mm}$ gauge width and $\sim 0.5 \mathrm{~mm}$ gauge thickness at the mid-radius position using spark-erosion. Tensile tests were performed at constant cross-head displacement rate with an initial strain rate of $1.0 \times 10^{-4} \mathrm{~s}^{-1}$.

The microstructures were examined using scanning electron microscopy (SEM) and transmission electron microscopy (TEM). The phases present in the alloy were evaluated by Xray diffraction (XRD). The sample surface was polished to a mirror-like finish for the XRD and SEM and the XRD analysis was conducted in a Philips PW1710 diffractometer using Cu Ka radiation and a graphite monochromatic crystal with a wavelength of $1.5406 \AA$. The TEM lamella 
was prepared by focus ion beam (FIB) milling and the sample was observed using a Tecnai G220 - SuperTwin FEI - 200 kV transmission microscope.

Samples processed through $10 \mathrm{HPT}$ turns were subsequently annealed at $573 \mathrm{~K}$ for $1 \mathrm{~h}$ in order to examine the formation of any different phases with XRD and SEM also used for microstructural characterization of the annealed composite. Dynamic hardness testing was used to determine the hardness of the different phases.

\section{Experimental results}

\subsection{Microstructural analysis}

Figure 1 shows backscattered electron (BSE) images of the centre (upper row) and edge (lower row) of the discs in the plane containing the axial and radial directions after different numbers of turns. It is anticipated that the half discs, initially composed of either pure $\mathrm{Al}$ or pure Mg, will develop a helical pattern after simple torsion when placed side by side within the anvil, and it is expected that the numbers of helices will increase and their thicknesses decrease as the number of turns increases. This trend is readily observed in the discs processed by $1 / 4$ and 1 turn of HPT in the first and second columns in Fig. 1 but unstable flow occurs during processing leading to an unpredicted mixing of the different phases and a significant increase in the interfacial area between $\mathrm{Mg}$ and $\mathrm{Al}$ after 5 or 10 turns. This effect is more pronounced at the edges of the discs. Despite this mixing of the phases, a lamellar structure is clearly identified at the centres of the discs processed up to 10 turns. It is also apparent that large areas of $\mathrm{Mg}$, corresponding to the darker phase, develop around the top and bottom surfaces at the edge of the sample and a significant mixing of $\mathrm{Mg}$ and $\mathrm{Al}$ takes place especially at the mid-plane position.

Figure 2 depicts a higher magnification secondary electron (SE) image of an area of mixing of phases near the edge of the sample processed to 10 turns of HPT. The composition of the analysed area was determined by EDS mapping of $\mathrm{Mg}$ and $\mathrm{Al}$ which revealed the existence of phases having thicknesses varying from less than 1 micron to a few microns. It should be noted 
also that these distinct phases are distributed as alternating lamellae which remain either rich in magnesium or aluminium even after 10 HPT revolutions.

A TEM lamella was prepared by FIB from an area containing thin phases of $\mathrm{Mg}$ and $\mathrm{Al}$ at the mid-radius position and Fig. 3 displays (a) a bright-field TEM image of the entire lamella, (b) an STEM image of a large area and (c) a bright-field TEM image of the interface region between the $\mathrm{Mg}$ (left) and $\mathrm{Al}$ (right) phases. Inspection of Fig. 3 reveals the development of elongated phases with thicknesses of $\sim 1 \mu \mathrm{m}$ in the disc-shaped sample processed through $10 \mathrm{HPT}$ turns. It is also evident that ultrafine grains are contained within both of these distinct phases. The STEM image depicts a clear contrast between the phases such that the aluminium phase appears brighter than the phase rich in magnesium. It is interesting to note also that elongated grains are present in the aluminium phase whilst the grains in the magnesium rich phase are mostly equiaxed.

\subsection{Mechanical properties}

The distributions of hardness in samples processed to different numbers of turns of HPT are presented by the histograms in Fig. 4. A bi-modal distribution is clearly observed since the indentations were sufficiently small to evaluate the hardness of each phase separately. It has been reported that the hardness of high purity aluminium processed by HPT to equivalent strains larger than $\sim 5$ lies within the range of $\sim 30-35 \mathrm{Hv}$ [19]. Thus, a hardness in the range of $\sim 30-35 \mathrm{kgf} / \mathrm{mm}^{2}$ is expected for the $\mathrm{Al}$ phase in the present experiments and this is very close to the lower peak for the distribution in the range of $\sim 25-30 \mathrm{kgf} / \mathrm{mm}^{2}$ as observed in the samples processed to $1 / 4$ and 1 turn. The hardness of the CP-Mg, determined by dynamic hardness, varied from 55 to 60 $\mathrm{kgf} / \mathrm{mm}^{2}[20]$ and this is similar to the higher peak in the distribution within the range of $\sim 55-65$ $\mathrm{kgf} / \mathrm{mm}^{2}$ recorded in the samples processed to $1 / 4$ and 1 turn. A shift towards higher hardness values is observed in the sample processed to 5 turns and this trend is even more evident after 10 HPT turns which displayed areas with hardness above $\sim 80 \mathrm{kgf} / \mathrm{mm}^{2}$. This increase in hardness in the samples processed to larger numbers of turns of HPT is attributed to the enhanced mixing between the phases that creates areas with very thin lamellar phases. 
Figure 5 shows an engineering stress vs. engineering strain curve determined by tensile testing of the material processed to 10 turns of HPT. The yield stress is above $100 \mathrm{MPa}$ and it is followed by a short steep hardening to an ultimate stress of 160 MPa. Despite the small strain hardening stage, the material displays a high total elongation due to a very significant postnecking deformation. This result provides a clear demonstration that the composite is very ductile even after 10 turns of HPT.

\subsection{Annealing}

A heat treatment at $573 \mathrm{~K}$ for $1 \mathrm{~h}$ triggered the formation of intermetallics in the composite processed to 10 turns. Figure 6 displays the X-ray diffraction pattern of the material before (upper) and after (lower) the annealing treatment. The as-processed material only exhibits peaks corresponding to either the aluminium or magnesium phases whereas the annealed composite also displays peaks corresponding to the intermetallic phases $\mathrm{Al}_{3} \mathrm{Mg}_{2}$ and $\mathrm{Al}_{12} \mathrm{Mg}_{17}$. Figure 7 shows a BSE image of an area of the interface between the Al-rich and Mg-rich phases. The different phases, including the intermetallics, are readily distinguished by the difference in brightness. The composition of different areas was estimated using EDS and the results reveal the presence of an aluminium phase with $\sim 4.6 \mathrm{wt}$. \% of magnesium in solid solution at point "1", a thick layer of an Al-rich intermetallic at point "2”, a thinner layer of a Mg-rich intermetallic at point "3" and a Mg-rich phase with aluminium in solid solution at points "4" and "5". It is worth noting that the amount of $\mathrm{Al}$ in solid solution in the Mg-rich phase decreases with increasing distance from the interface with the other phases. Indentation marks from dynamic hardness tests are also observed in Fig. 7 and these indentation sizes are clearly smaller in the intermetallic area due to their higher hardness compared to both the Mg-rich and the Al-rich phases.

Figure 8 shows histograms for the distributions of hardness in the material processed by 10 turns of HPT before and after the annealing treatment. Thus, the as-processed composite displays hardness within the interval of $\sim 20-100 \mathrm{kgf} / \mathrm{mm}^{2}$ whereas the annealed material displays a broader distribution of hardness ranging from $\sim 40$ to $\sim 270 \mathrm{kgf} / \mathrm{mm}^{2}$. These ranges show the increasing hardness of the composite through the annealing heat treatment. The hardness of the 
Mg-rich, the Al-rich and the intermetallic phases were estimated by the average of several indentations and the hardness was $\sim 58 \mathrm{kgf} / \mathrm{mm}^{2}$ in the Mg-rich phase, $\sim 89 \mathrm{kgf} / \mathrm{mm}^{2}$ in the Alrich phase and $\sim 229 \mathrm{kgf} / \mathrm{mm}^{2}$ in the intermetallics. In practice, it was not possible to distinguish the separate hardness of each intermetallic phase due to the small sizes of the indentations.

\section{Discussion}

The processing of $\mathrm{Mg} / \mathrm{Al}$ composites by HPT was documented in earlier reports [11-14] but these other investigations examined the stacking of individual whole discs whereas the present investigation used half discs which were placed side-by-side within the cavity contained in the upper surface of the lower HPT anvil. This difference is important because homogeneous simple torsional deformation is not expected to promote the mixing of phases when using stacked discs. By contrast, it is readily apparent that a progressive mixing is likely to occur between adjacent half discs due to the development of conventional helical patterns during HPT processing [2127]. A progressive mixing of phases with concomitant phase thickness reduction is also predicted and was observed during processing of different metallic materials placed side by side in tube high-pressure shearing [18]. This gradual mixing of the phases is observed in the early stages of processing but, with increasing numbers of turns, a pronounced mixing is observed which is larger than expected. This effect is more evident around the interfaces of the different phases and leads to the formation of very thin layers of each phase. These observations show that the deformation imposed during HPT is highly heterogeneous and the effective strain may be significantly larger than predicted through conventional modeling. In practice, this effect is consistent with the reported mixing of phases after large numbers of turns of HPT even in stacked discs [11, 12, 28]. Local plastic flow instabilities may develop due to differences in the flow stresses and incompatibilities of deformation at the interface between the phases. It is worth noting also that plastic flow instabilities in simple shear deformation have been predicted around inclusions through finite element modelling [29].

The present results provide no conclusive evidence for the formation of intermetallics during HPT processing up to 10 turns although the $\mathrm{Al}_{3} \mathrm{Mg}_{2}$ and the $\mathrm{Al}_{12} \mathrm{Mg}_{17}$ phases are the 
expected stable phases for a mixture of Mg-50\% vol. Al. As the processing was conducted at room temperature and the local sample heating is anticipated to be $<20^{\circ} \mathrm{C}$ [30-32], it is expected that the nucleation and growth of different phases will be hindered. It is worth noting also that intermetallic formation was reported in a composite of 1050 aluminium alloy and ZK60 magnesium alloy processed up to 20 turns of HPT using stacked discs [11, 12]. The present experiments were conducted using half discs placed next to each other which reduces the initial contact area between the different metals. This reduces the interfacial area and may hinder the reaction between the different metals. Intermetallic formation was observed in the present study after heat treatment at $573 \mathrm{~K}$ for $1 \mathrm{~h}$ and the $\mathrm{Al}$-rich intermetallic $\mathrm{Al}_{3} \mathrm{Mg}_{2}$ is thicker than the $\mathrm{Mg}$ rich $\mathrm{Al}_{12} \mathrm{Mg}_{17}$ which agrees with data reported in $\mathrm{Mg} / \mathrm{Al}$ diffusion couples [33].

The composites produced in this investigation exhibit interesting mechanical properties. Thus, the pure metal phases display low hardness in the early stages of processing but the hardness increases with the severe mixing of phases. Although magnesium and aluminium alloys tend to exhibit brittle behaviour after processing by HPT, pure aluminium and pure magnesium are ductile even after severe plastic deformation. As a consequence, the $\mathrm{Mg}$ / Al composite displays a significant elongation even after 10 turns of HPT as shown in Fig. 5.

The hardness of the composite may be increased by a heat treatment to induce the formation of harder intermetallics. Moreover, heat treatment also promotes the formation of a gradient of solid solution in the pure metal phases. As a consequence, the annealed material displays a broad range of distributions of hardness as documented in Fig. 8. The hardness of the Mg-rich phase does not change significantly but the Al-rich phase hardened significantly due to the Mg in solution. Thus, the annealed composite displays a microstructure containing a soft phase (Mg alloy), a phase with an intermediate strength (Al alloy) and hard phases (intermetallics). The fraction of each phase can be controlled through the use of different thermal treatment temperatures and times. This means that composites with different mechanical properties may be effectively processed by tailoring the HPT and heat treatment conditions.

\section{Summary and conclusions}


1. A Mg / Al composite was produced with a good mixing of the phases by processing half discs of each pure metal placed adjacent to each other in HPT. The thickness of each phase in the composite decreases with increasing numbers of turns. The results show plastic instabilities promote severe mixing of the phases after 5 and 10 turns of HPT.

2. Ultrafine-grains were formed within each phase and intermetallics were not present up to 10 turns of HPT.

3. The hardness of each phase was consistent with the hardness of the pure metals processed by HPT up to 1 turn but there was an increase in hardness after 10 turns due to the formation of very thin layers of each phase. Mechanical testing showed the composite displayed a high elongation in tension of almost $20 \%$.

4. Annealing at $573 \mathrm{~K}$ for $1 \mathrm{~h}$ promoted the formation of a solid solution in the pure metal phases and the formation of $\mathrm{Al}_{3} \mathrm{Mg}_{2}$ and $\mathrm{Al}_{12} \mathrm{Mg}_{17}$ intermetallics. A broad range of hardness values were observed in the composite after annealing at $573 \mathrm{~K}$.

\section{Acknowledgements}

The authors acknowledge the Center of Microscopy at the Universidade Federal de Minas Gerais (http://www.microscopia.ufmg.br) for providing the equipment and technical support for experiments involving electron microscopy. RBF acknowledges financial support from CNPq (grant \#400407/2016-7), FAPEMIG (grant \#APQ-00580-15) and Serrapilheira Institute (grant \#Serra-1709-17750). 


\section{References}

[1] A.P. Zhilyaev, T.G. Langdon, Using high-pressure torsion for metal processing: Fundamentals and applications Progress in Materials Science, 53 (2008) 893-979. [2] S. Panda, L.S. Toth, J.X. Zou, T. Grosdidier, Effect of Strain Heterogeneities on Microstructure, Texture, Hardness, and H-Activation of High-Pressure Torsion Mg Consolidated from Different Powders, Materials, 11 (2018).

[3] S. Panda, J.-J. Fundenberger, Y. Zhao, J. Zou, L.S. Toth, T. Grosdidier, Effect of initial powder type on the hydrogen storage properties of high-pressure torsion consolidated Mg, International Journal of Hydrogen Energy, 42 (2017) 22438-22448. [4] M. Khajouei-Nezhad, M.H. Paydar, R. Ebrahimi, P. Jenei, P. Nagy, J. Gubicza, Microstructure and mechanical properties of ultrafine-grained aluminum consolidated by high-pressure torsion, Materials Science and Engineering: A, 682 (2017) 501-508. [5] H. Asgharzadeh, S.-H. Joo, J.-K. Lee, H.S. Kim, Consolidation of Cu-based amorphous alloy powders by high-pressure torsion, Journal of Materials Science, 50 (2015) 3164-3174.

[6] A.P. Zhilyaev, A.A. Gimazov, G.I. Raab, T.G. Langdon, Using high-pressure torsion for the cold-consolidation of copper chips produced by machining, Materials Science and Engineering: A, 486 (2008) 123-126.

[7] M.M. de Castro, A.P. Carvalho, P.H.R. Pereira, A.C. Isaac Neta, R.B. Figueiredo, T.G. Langdon, Consolidation of Magnesium and Magnesium Alloy Machine Chips Using High-Pressure Torsion, Materials Science Forum, 941 (2019) 851-856.

[8] H. Asgharzadeh, H. Faraghi, H.S. Kim, Fabrication of Fullerene-Reinforced Aluminum Matrix Nanocomposites, Acta Metallurgica Sinica (English Letters), 30 (2017) 973-982.

[9] M. Ashida, Z. Horita, T. Kita, A. Kato, Production of Al/Al2O3 Nanocomposites through Consolidation by High-Pressure Torsion, Materials Transactions, 53 (2012) 1316.

[10] J.M. Cubero-Sesin, Z. Horita, Powder consolidation of Al-10wt\% Fe alloy by High-Pressure Torsion, Materials Science and Engineering: A, 558 (2012) 462-471. [11] J.K. Han, H.J. Lee, J.I. Jang, M. Kawasaki, T.G. Langdon, Micro-mechanical and tribological properties of aluminum-magnesium nanocomposites processed by highpressure torsion, Materials Science and Engineering a-Structural Materials Properties Microstructure and Processing, 684 (2017) 318-327.

[12] M. Kawasaki, J.I. Jang, Micro-Mechanical Response of an Al-Mg Hybrid System Synthesized by High-Pressure Torsion, Materials, 10 (2017).

[13] M. Kawasaki, B. Ahn, H. Lee, A.P. Zhilyaev, T.G. Langdon, Using high-pressure torsion to process an aluminum-magnesium nanocomposite through diffusion bonding, Journal of Materials Research, 31 (2016) 88-99.

[14] X.G. Qiao, X. Li, X.Y. Zhang, Y. Chen, M.Y. Zheng, I.S. Golovin, N. Gao, M.J. Starink, Intermetallics formed at interface of ultrafine grained $\mathrm{Al} / \mathrm{Mg}$ bi-layered disks processed by high pressure torsion at room temperature, Materials Letters, 181 (2016) 187-190.

[15] T. Tokunaga, K. Kaneko, Z. Horita, Production of aluminum-matrix carbon nanotube composite using high pressure torsion, Materials Science and Engineering: A, 490 (2008) 300-304.

[16] R.B. Figueiredo, S. Sabbaghianrad, A. Giwa, J.R. Greer, T.G. Langdon, Evidence for exceptional low temperature ductility in polycrystalline magnesium processed by severe plastic deformation, Acta Materialia, 122 (2017) 322-331. 
[17] R.B. Figueiredo, P.R. Cetlin, T.G. Langdon, Using finite element modeling to examine the flow processes in quasi-constrained high-pressure torsion, Materials Science and Engineering A, 528 (2011) 8198-8204.

[18] Z. Li, P.F. Zhang, H. Yuan, K. Lin, Y. Liu, D.L. Yin, J.T. Wang, T.G. Langdon, Principle of one-step synthesis for multilayered structures using tube high-pressure shearing, Materials Science and Engineering: A, 658 (2016) 367-375.

[19] Y. Ito, Z. Horita, Microstructural evolution in pure aluminum processed by highpressure torsion, Materials Science and Engineering: A, 503 (2009) 32-36.

[20] C.L.P. Silva, I.C. Tristão, S. Sabbaghianrad, S.A. Torbati-Sarraf, R.B. Figueiredo, T.G. Langdon, Microstructure and Hardness Evolution in Magnesium Processed by HPT, Materials Research, 20 (2017) 2-7.

[21] R. Kulagin, Y. Beygelzimer, A. Bachmaier, R. Pippan, Y. Estrin, Benefits of pattern formation by severe plastic deformation, Applied Materials Today, 15 (2019) 236-241.

[22] Y. Cao, M. Kawasaki, Y.B. Wang, S.N. Alhajeri, X.Z. Liao, W.L. Zheng, S.P. Ringer, Y.T. Zhu, T.G. Langdon, Unusual macroscopic shearing patterns observed in metals processed by high-pressure torsion, Journal of Materials Science, 45 (2010) 4545-4553.

[23] Y. Cao, Y.B. Wang, S.N. Alhajeri, X.Z. Liao, W.L. Zheng, S.P. Ringer, T.G. Langdon, Y.T. Zhu, A visualization of shear strain in processing by high-pressure torsion, Journal of Materials Science, 45 (2010) 765-770.

[24] Y. Huang, M. Kawasaki, A. Al-Zubaydi, T.G. Langdon, Effect of anvil roughness on the flow patterns and hardness development in high-pressure torsion, Journal of Materials Science, 49 (2014) 6517-6528.

[25] Y. Huang, M. Kawasaki, T.G. Langdon, An evaluation of the shearing patterns introduced by different anvil alignments in high-pressure torsion, Journal of Materials Science, 49 (2014) 3146-3157.

[26] Y. Huang, M. Kawasaki, T.G. Langdon, Influence of Anvil Alignment on Shearing Patterns in High-Pressure Torsion, Advanced Engineering Materials, 15 (2013) 747755.

[27] Y. Huang, M. Kawasaki, T.G. Langdon, An investigation of flow patterns and hardness distributions using different anvil alignments in high-pressure torsion, Journal of Materials Science, 48 (2013) 4533-4542.

[28] M. Kawasaki, J.-K. Han, D.-H. Lee, J.-i. Jang, T.G. Langdon, Fabrication of nanocomposites through diffusion bonding under high-pressure torsion, Journal of Materials Research, (2018) 1-11.

[29] R. Kulagin, Y. Beygelzimer, Y. Ivanisenko, A. Mazilkin, H. Hahn, Modelling of High Pressure Torsion using FEM, Procedia Engineering, 207 (2017) 1445-1450. [30] R.B. Figueiredo, P.H.R. Pereira, M.T.P. Aguilar, P.R. Cetlin, T.G. Langdon, Using finite element modeling to examine the temperature distribution in quasi-constrained high-pressure torsion, Acta Materialia, 60 (2012) 3190-3198.

[31] P.H.R. Pereira, R.B. Figueiredo, Y. Huang, P.R. Cetlin, T.G. Langdon, Modeling the temperature rise in high-pressure torsion, Materials Science and Engineering A, 593 (2014) 185-188.

[32] K. Edalati, Y. Hashiguchi, P.H.R. Pereira, Z. Horita, T.G. Langdon, Effect of temperature rise on microstructural evolution during high-pressure torsion, Materials Science and Engineering a-Structural Materials Properties Microstructure and Processing, 714 (2018) 167-171. 
[33] L. Wang, Y. Wang, P. Prangnell, J. Robson, Modeling of Intermetallic Compounds Growth Between Dissimilar Metals, Metallurgical and Materials Transactions A, 46 (2015) 4106-4114. 


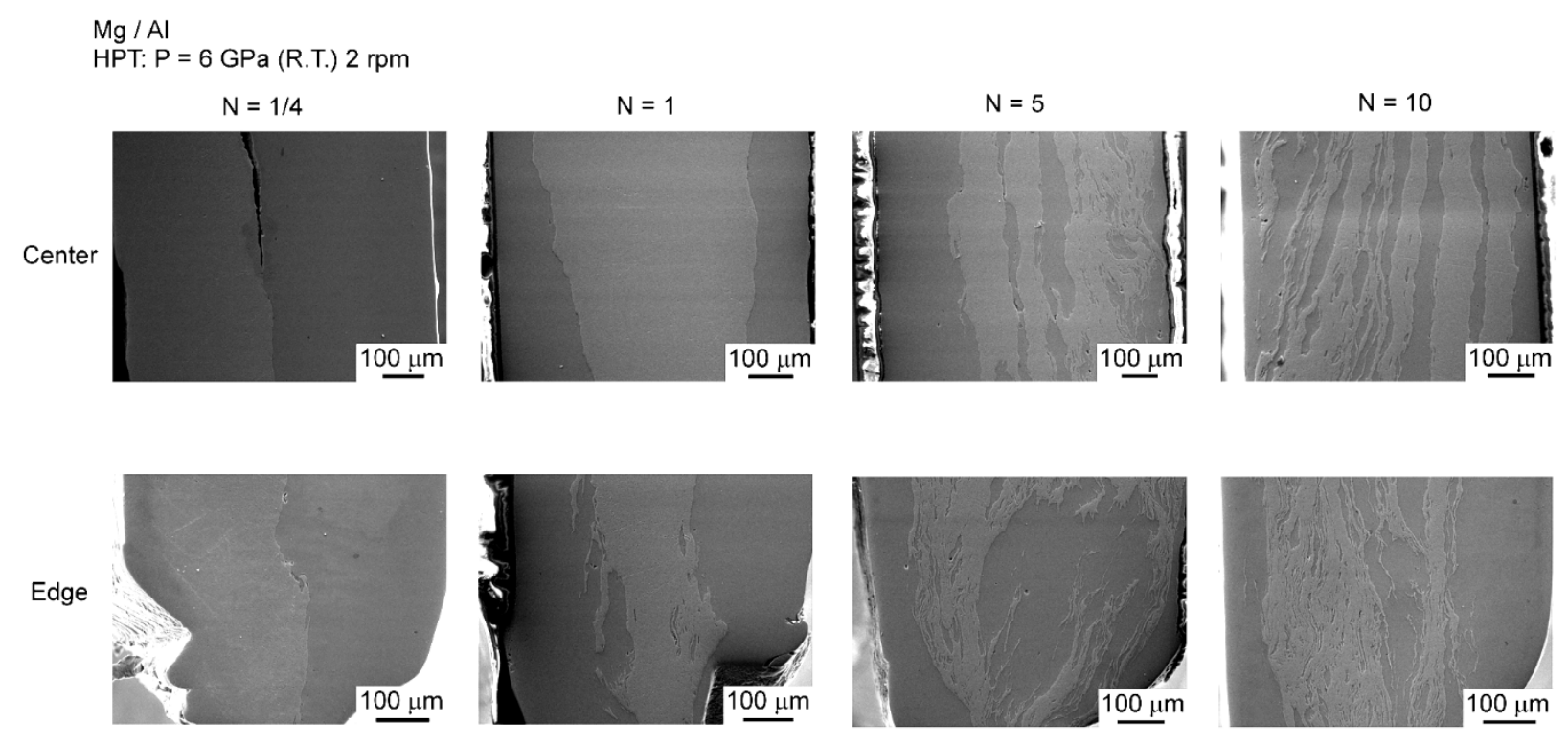

Figure 1 - BSE images of the microstructure of $\mathrm{Mg}-50 \%$ vol. Al composites at different levels of shear straining by HPT. 


\section{$\mathrm{Mg} / \mathrm{Al}$}

HPT: $N=10$ (R.T.) P $=6 \mathrm{GPa}$
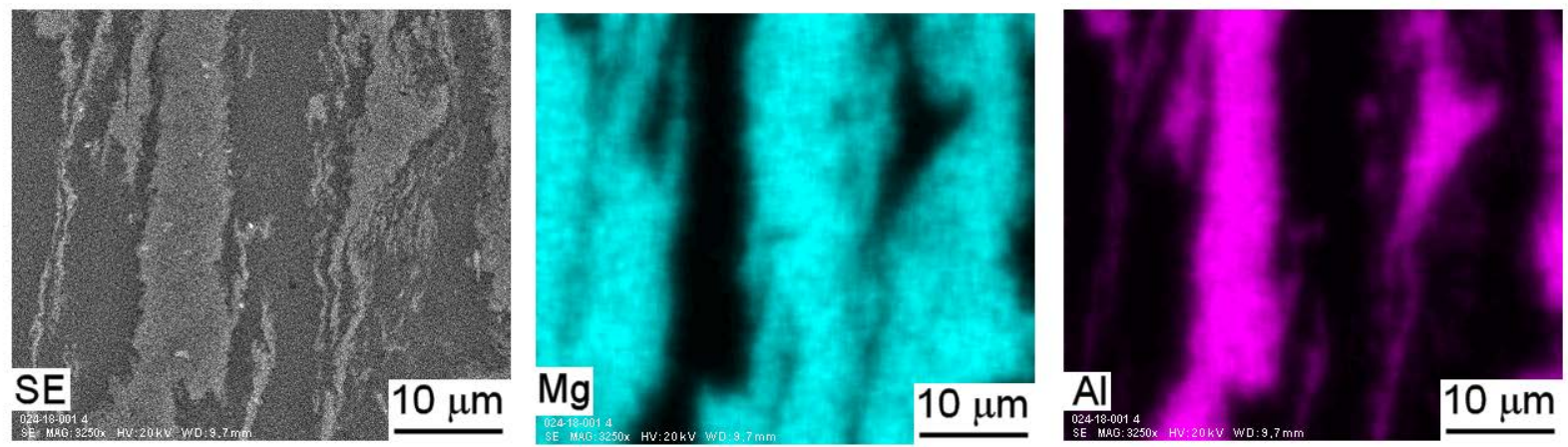

Figure 2-SE image and EDS mapping of $\mathrm{Mg}$ and $\mathrm{Al}$ at mid-radius position of the sample processed to 10 turns of HPT. 
$\underline{\mathrm{Mg} / \mathrm{Al}}$

$\overline{\mathrm{HPT}}: \mathrm{N}=10$ (R.T.) $\mathrm{P}=6 \mathrm{GPa}$

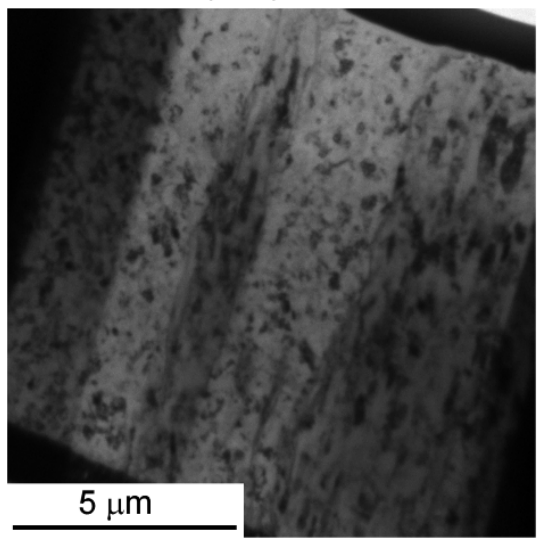

(a)

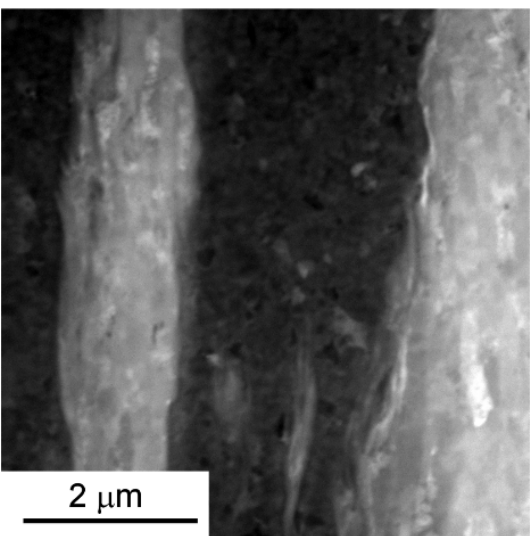

(b)

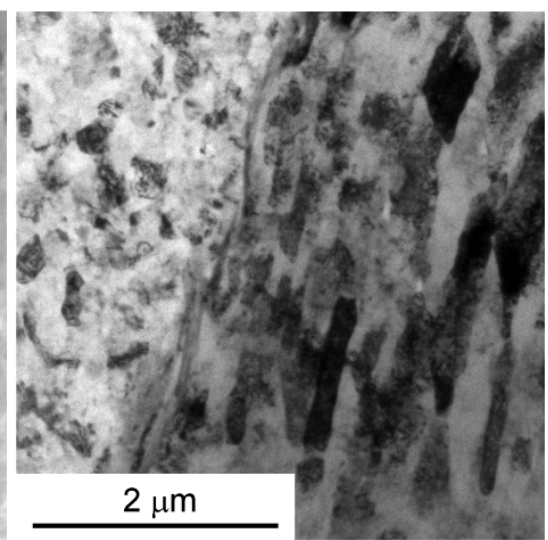

(c)

Figure 3 - TEM bright field image of the (a) whole lamella, (b) STEM image of the different phases and (c) higher magnification at the interface between $\mathrm{Mg}$ and $\mathrm{Al}$ phases. 


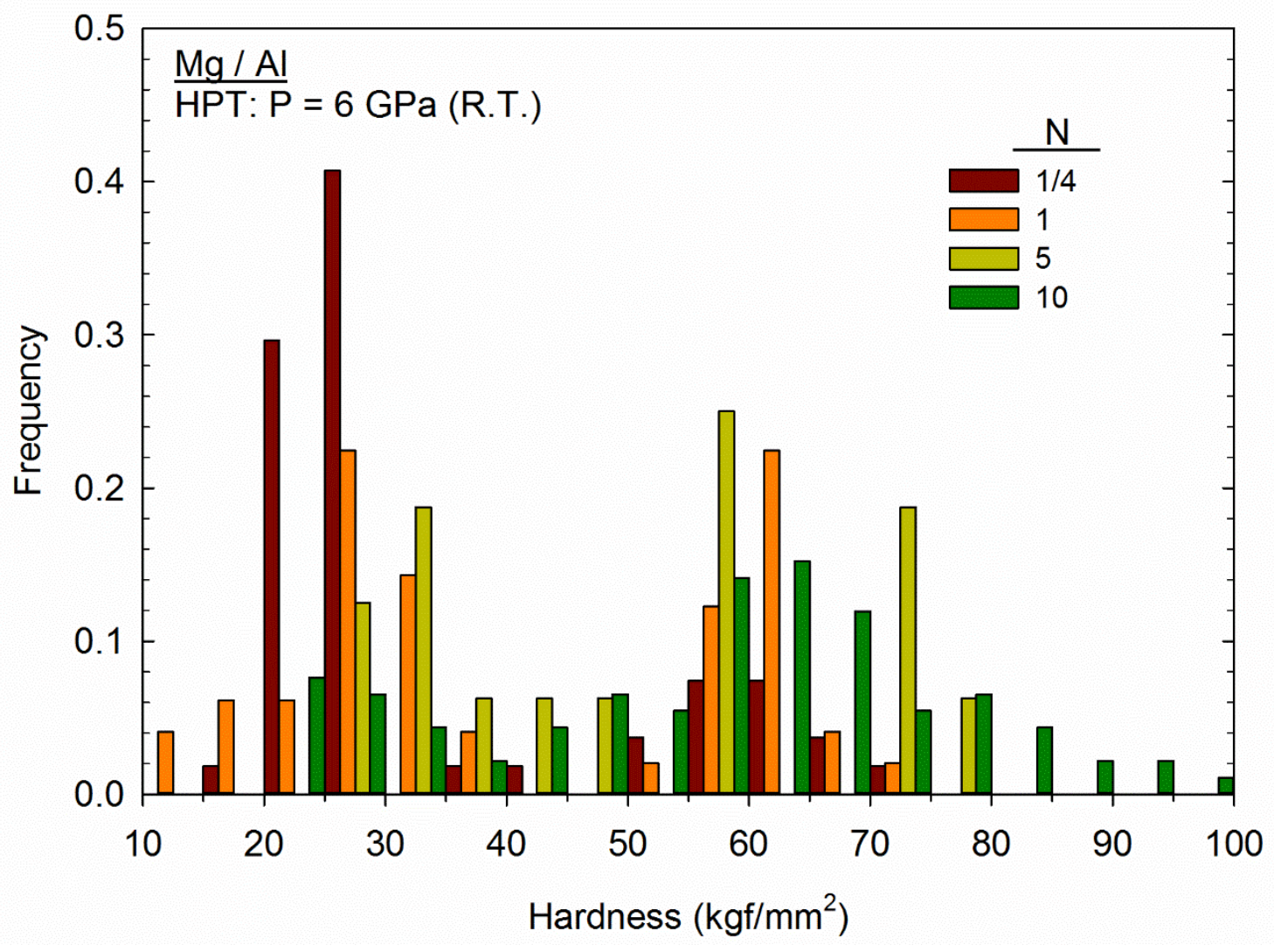

Figure 4 - Distribution of hardness in samples processed to different number of turns of HPT. 


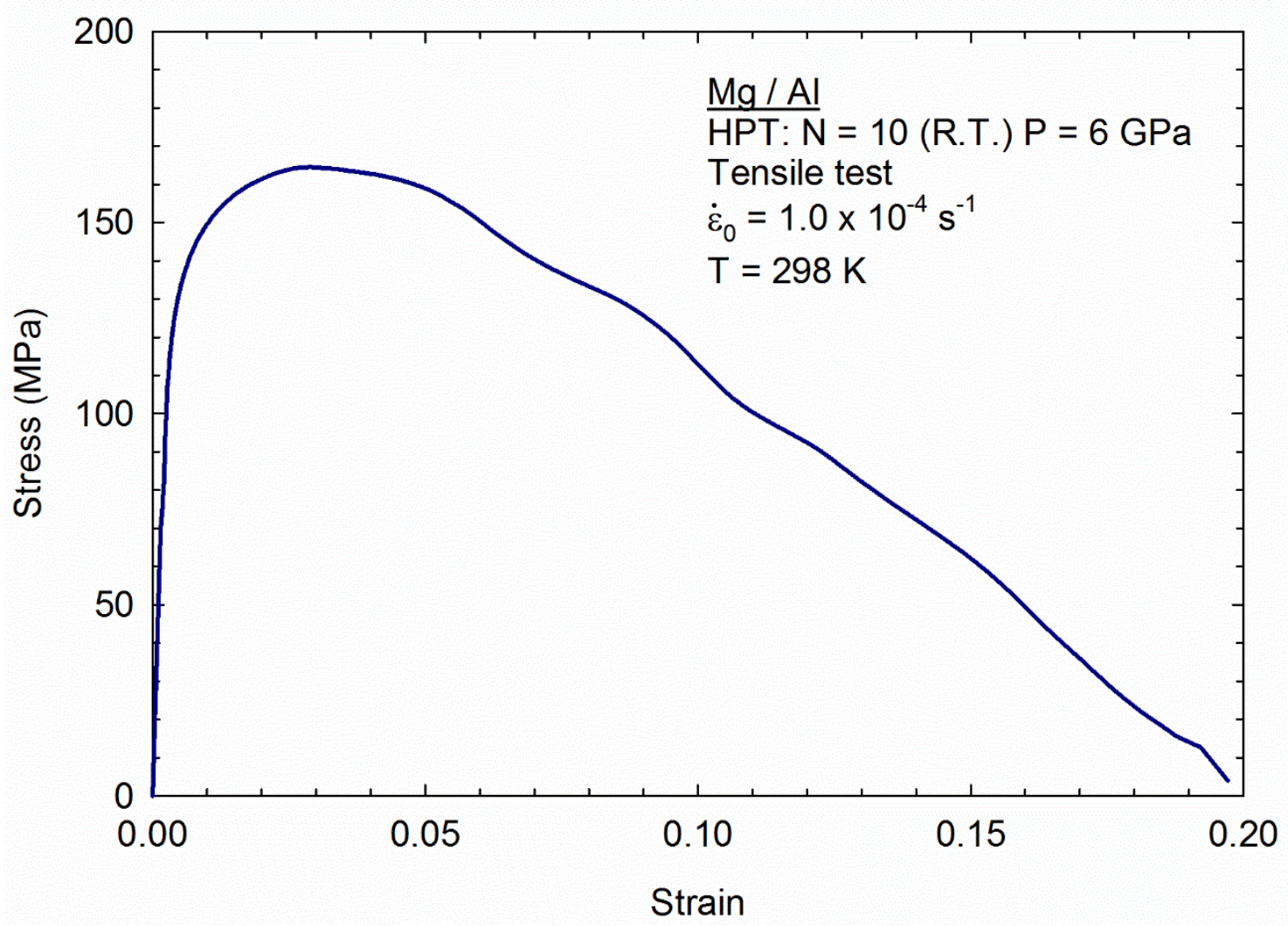

Figure 5 - Stress vs strain curve of the composite processed to 10 turns of HPT. 


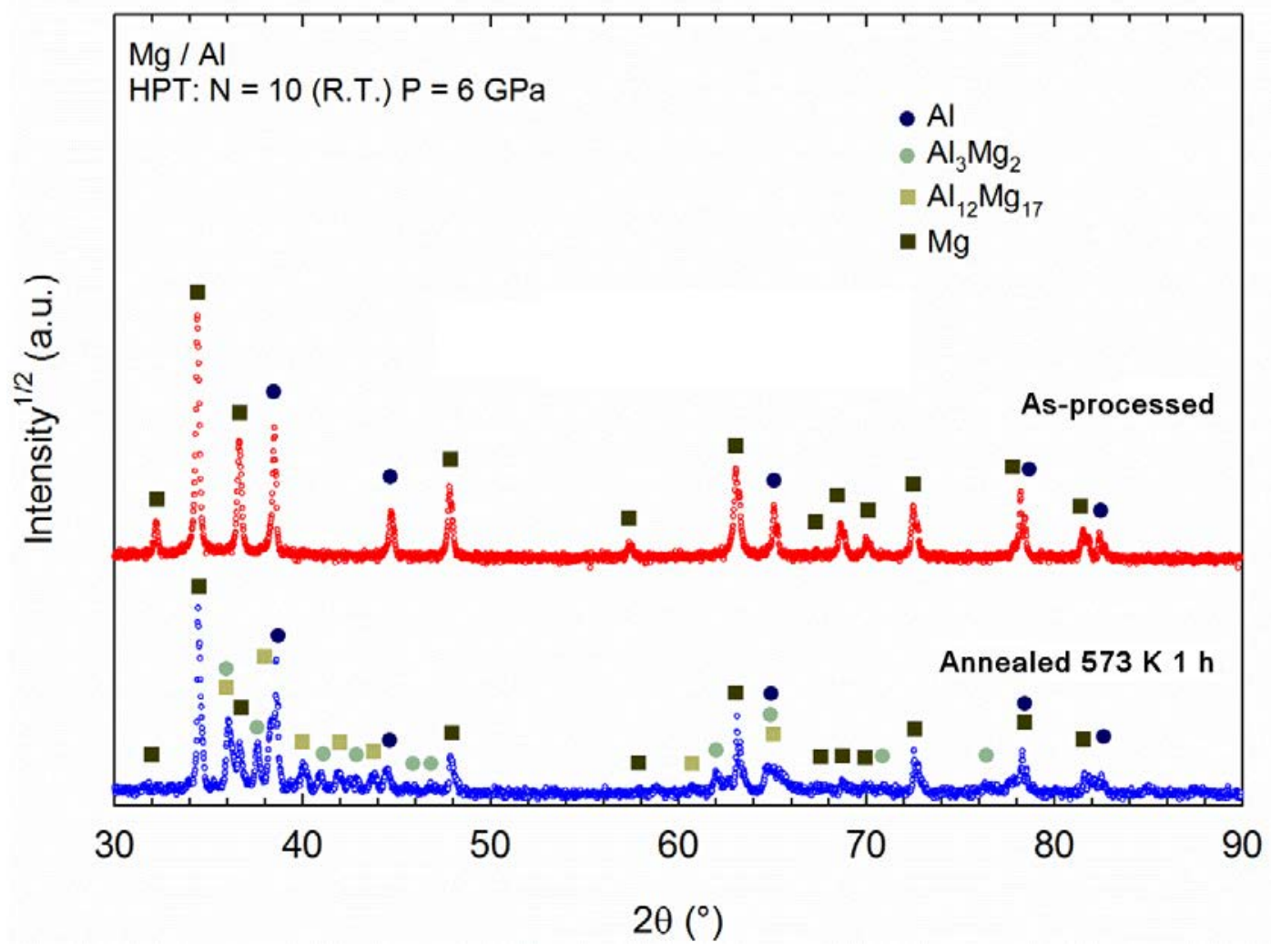

Figure 6 -X-ray diffraction pattern of the material processed by 10 turns of HPT before and after annealing at $573 \mathrm{~K}$ for 1 hour. 
$\underline{\mathrm{Mg} / \mathrm{Al}}$

HPT: N = 10 (R.T.) P = $6 \mathrm{GPa}$

Annealing: $573 \mathrm{~K}(1 \mathrm{~h})$

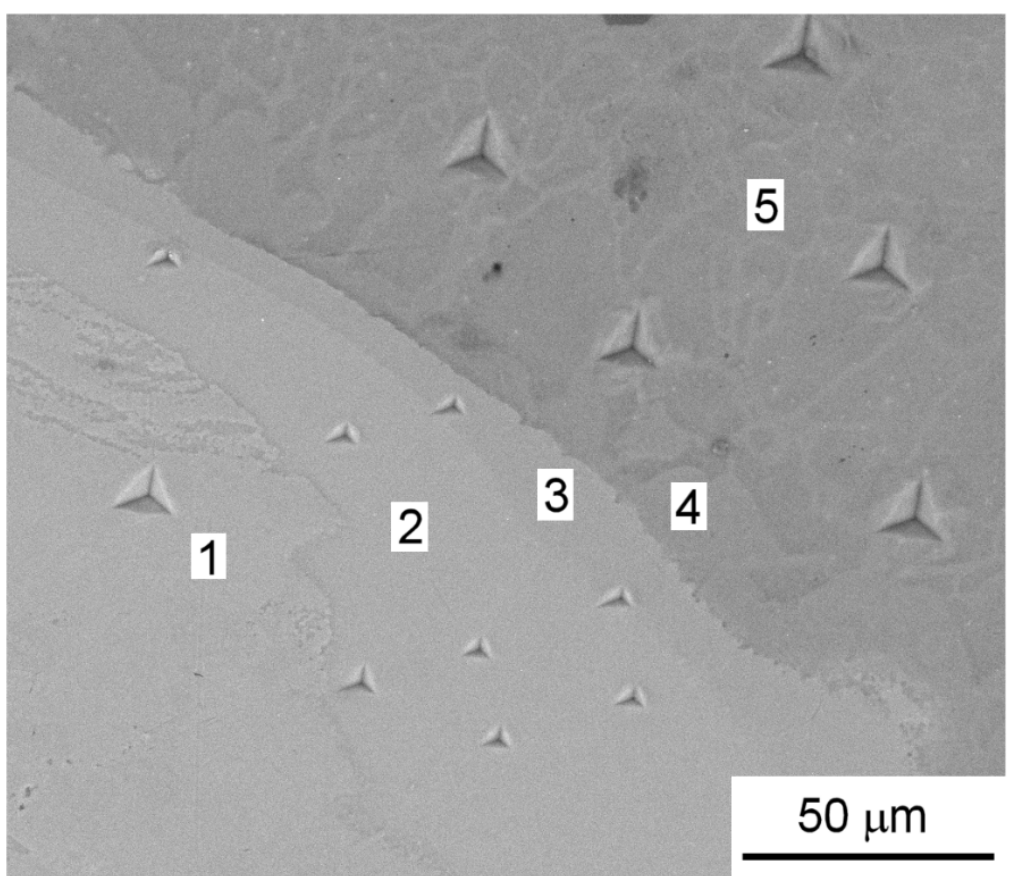

Composition in wt. \%

$1 \quad \frac{\mathrm{Mg}}{4.6} \frac{\mathrm{Al}}{95.4}$

$2 \quad 36.7 \quad 63.3$

$3 \quad 55.144 .9$

$4 \quad 96.1 \quad 3.9$

$5 \quad 99.4 \quad 0.6$

Figure 7 - BSE image and EDS composition of different areas in the material processed by 10 turns of HPT and annealed at $573 \mathrm{~K}$. 


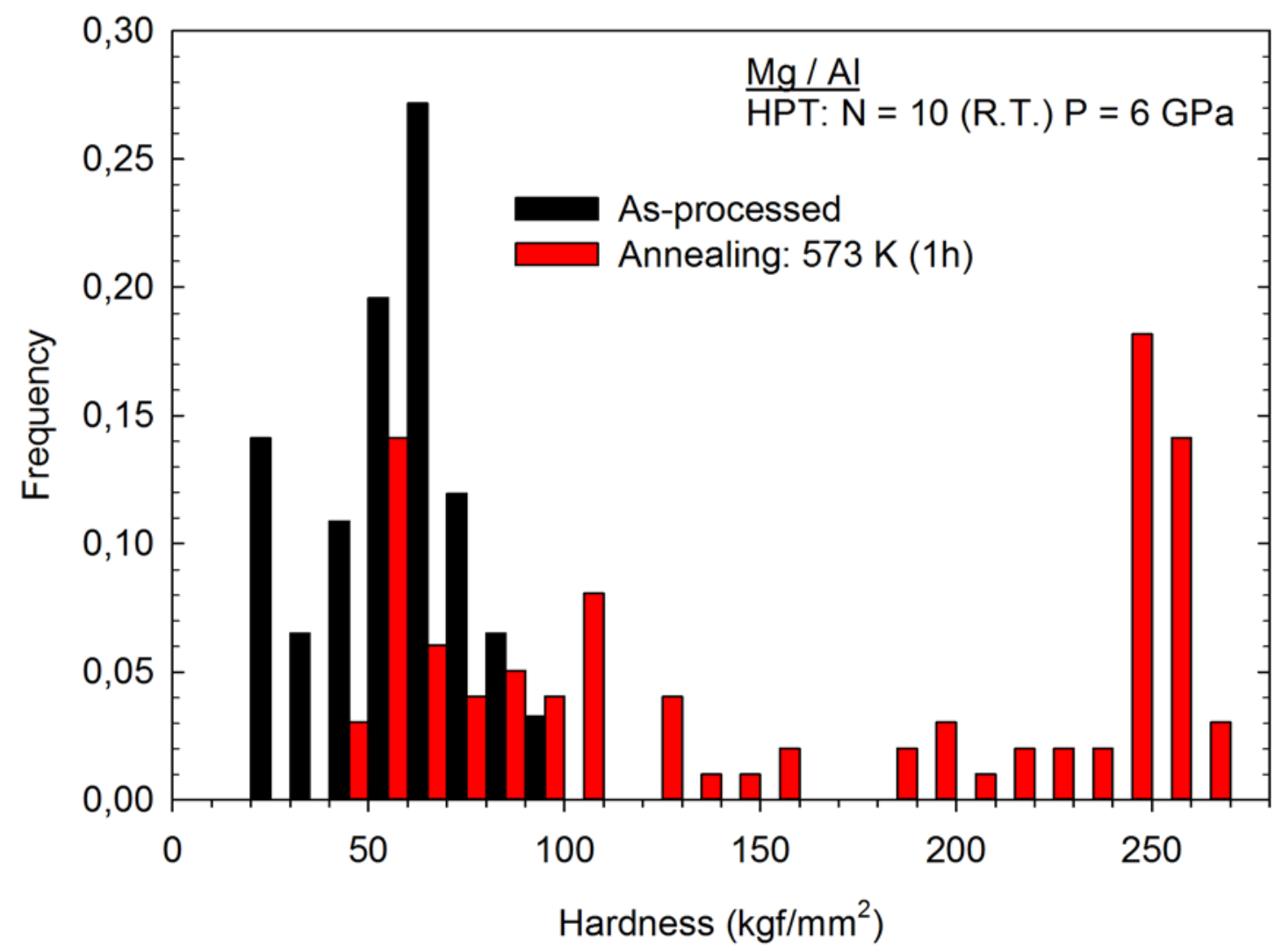

Figure 8 - Frequency of hardness distribution in the $\mathrm{Mg} / \mathrm{Al}$ composite before and after thermal treatment at $573 \mathrm{~K}$. 